\title{
Práticas de cuidado e cultivo da atenção com crianças
}

\section{Practices of care and cultivation of attention with children}

DOI: http://dx.doi.org/10.5965/198431781642020166

\author{
Luciana Vieira Caliman \\ Universidade Federal do Espírito Santo - UFES \\ calimanluciana@gmail.com | ORCID | LATTES \\ Janaína Mariano César \\ Universidade Federal do Espírito Santo - UFES \\ jhanainacesar@gmail.com | ORCID | LATTES \\ Virgínia Kastrup \\ Universidade Federal do Rio de Janeiro - UFRJ \\ virginia.kastrup@gmail.com | ORCID | LATTES
}

\section{RESUMO}

Este estudo analisa uma experiência realizada no Brasil, na qual crianças diagnosticadas com Transtorno de Déficit de Atenção e Hiperatividade (TDAH) e outros problemas relacionais, usuárias de um Centro de Atenção Psicossocial Infantojuvenil (CAPSi), participam de uma oficina de leitura de literatura. A proposta da Oficina da Palavra é oferecer uma alternativa ao uso da medicação como modo central de tratamento, por meio de um dispositivo grupal e participativo de leitura e também de cuidado. A oficina foi realizada como uma pesquisa-intervenção baseada no método da cartografia. Através da proposição de um dispositivo grupal de cuidado, dá-se relevo à dimensão conjunta da atenção e a importância de construir ecossistemas atencionais nos quais a atenção a si e aos outros é cultivada. A partir de uma perspectiva ecológica que ultrapassa o viés individualista e naturalista da atenção, o cuidado dos problemas atencionais surge como um trabalho de cultivo de correspondência e atenção conjunta concentrada e aberta, envolvendo a construção de ecossistemas atencionais favoráveis.

Palavras-chave: Atenção; Cuidado; Crianças; Ecologia da atenção;

\section{ABSTRACT}

This study analyzes an experience carried out in Brazil in which children diagnosed with Attention Deficit Hyperactivity Disorder (ADHD) and relational problems, users of a Psychosocial Care Center for Children and Adolescents (CAPSi), participate in an atelier of literature reading. The proposal of "Oficina da Palavra" is to offer an alternative to the use of medicines as the central mode of treatment, through a collective and participative device of reading and care. The atelier was held as an intervention research based on the cartography method. It emphasizes the joint dimension of attention and the importance of building ecosystems in which attention to oneself and to others is cultivated. From an ecological perspective that goes beyond individualistic and naturalistic views of attention, care for attention problems emerges as a work of cultivating correspondence and joint, opened concentrated attention, involving the construction of favorable ecosystems.

Keywords: Attention; Care; Children; Attention ecology; 
Este estudo analisa uma experiência realizada no Brasil, na qual crianças diagnosticadas com Transtorno de Déficit de Atenção e Hiperatividade (TDAH) e outros problemas relacionais, usuárias de um Centro de Atenção Psicossocial Infantojuvenil (CAPSi) ${ }^{1}$, participam de uma oficina de leitura de literatura. A proposta da Oficina da Palavra é oferecer uma alternativa ao uso da medicação como modo central de tratamento, por meio de um dispositivo grupal e participativo de leitura e também de cuidado.

Cada vez mais os CAPSi(s) acolhem crianças encaminhadas pelas escolas: crianças sobre as quais é dito que não aprendem, não conseguem prestar atenção na aula, não param quietas, são agressivas e "impossíveis". No CAPSi da cidade de Vitória, no estado do Espírito Santo, onde foi realizado o trabalho, muitas vezes o encaminhamento vem das escolas com a demanda explícita de um laudo médico e de prescrição de medicamentos. Outras vezes as crianças chegam com algum diagnóstico e já são usuárias de psicotrópicos, inclusive de metilfenidato. $O$ metilfenidato é atualmente o psicoestimulante mais consumido no Brasil e no mundo (ORTEGA et al, 2017). No estado do Espírito Santo, é incluído na lista de medicamentos especiais, sendo dispensado pelo Sistema Único de Saúde (CALIMAN; DOMITROVIC, 2013). No CAPSi de Vitória, sobressai na população atendida o número de crianças diagnosticadas com TDAH e de queixas escolares em torno dos problemas atencionais (CHAVES; CALIMAN, 2017).

Os estudos emblemáticos de Conrad $(1975,2006)$ apontam o lugar central do par TDAH-metilfenidato nos processos de medicalização da educação e dos comportamentos infantis desviantes. No Brasil, o metilfenidato foi liberado para o tratamento do TDAH em 1998. Desde então, os números do consumo crescem ano após ano. Frente a este cenário, os discursos acadêmicos e de profissionais da saúde e da educação encontram-se polarizados entre aqueles que defendem sem

${ }^{1}$ Os Centros de Atenção Psicossocial (CAPS) fazem parte do Sistema Único de Saúde (SUS) do Brasil, pertencendo a rede pública e integrada de cuidados em saúde mental. O CAPS infantojuvenil (CAPSi) é especializado no atendimento de crianças e jovens. 
críticas o diagnóstico biomédico de TDAH e os que questionam a própria existência do transtorno (ORTEGA et al, 2018). Em um polo, o metilfenidato é visto como o tratamento mais indicado para o TDAH e para os problemas atencionais que dificultam a aprendizagem na escola; no outro polo, ele é descrito como a "pílula da obediência", exemplo maior de um indesejável processo de medicalização da educação.

Procurando ir além desta dicotomia, o presente estudo reconhece que ecossistemas atencionais precários podem produzir problemas atencionais e sofrimento na relação que certas crianças estabelecem com a escola, consigo mesmas e com os outros. No entanto, está fora de seu escopo discutir a notável expansão do diagnóstico de TDAH e os efeitos complexos e contraditórios produzidos na vida das pessoas diagnosticadas, seus familiares e instituições de pertencimento. Também não recusa a legitimidade do uso do metilfenidato em certas circunstâncias e projetos terapêuticos. Ao ir além da dicotomia legitimidade/não legitimidade do TDAH e do tratamento medicamentoso, problematiza as formas individualizantes de compreender e tratar dos problemas da atenção e a centralidade quase sempre ocupada pelo medicamento. Através da proposição de um dispositivo grupal de cuidado, dá-se relevo à dimensão conjunta da atenção e a importância de construir ecossistemas atencionais nos quais a atenção a si e aos outros é cultivada.

Para desnaturalizar a centralidade da medicação no tratamento dos problemas que envolvem a atenção, é preciso começar por colocar em discussão o que entendemos por atenção e seu funcionamento. Curiosamente, tal problema tem sido pouco considerado pelos estudos sobre o TDAH, que na maioria das vezes não se ocupam da discussão conceitual e consideram a atenção algo evidente, que dispensa conceituação. A referência a um funcionamento binário atenção-desatenção parece suficiente. No caso das queixas escolares, a atenção é entendida como uma capacidade individual de focalização, vista como condição para que a aprendizagem aconteça. Considera-se que a criança não aprende porque não presta atenção à tarefa, não está focada suficientemente nela. Todavia, como 
assinalaram autores como W. James (1950), H. Bergson (1922/2001) e S. Freud (1912), bem como os estudos atuais de P. Vermersch (2002), N. Depraz (2010), F. Varela, E. Thompson, E. Rosch (1993), e J-P. Lachaux (2013), a atenção possui diversos gestos e nuances, para além do binarismo atenção-desatenção e do gesto de prestar atenção a tarefas pré-definidas. A atenção é um processo bem mais complexo.

Tomamos como ponto de partida a perspectiva ecológica proposta por $\mathrm{Y}$. Citton (2014) que, a nosso ver, ressoa com os trabalhos de T. Ingold (2018) e D. Boullier (2010). Em tais estudos a atenção não é um processo cognitivo individual e natural, mas tem uma dimensão coletiva e conjunta. A atenção é coletiva na medida em que resulta de um jogo complexo que envolve vetores heterogêneos - materiais, midiáticos, tecnológicos, políticos, econômicos e estéticos. Ela é também conjunta por ser produzida por meio de práticas relacionais. Sendo um exercício relacional basilar na constituição de nossa "co-respondência" com o mundo, ela assume um lugar fundamental na educação e na escola (INGOLD, 2018). Veremos que tal exercício será de grande importância quando o objetivo é propor dispositivos de cuidado voltados para os problemas atencionais e sua dimensão relacional, que sejam alternativas à centralidade do tratamento medicamentoso. Assim, na Oficina da Palavra buscamos constituir um ecossistema atencional favorável, marcado pelo cultivo de uma atenção conjunta entre os seus participantes, capaz de acolher gestos atencionais distintos da focalização. A Oficina constitui um dispositivo grupal que acolhe a distração, movimento atencional frequentemente considerado prejudicial à aprendizagem. Assume-se o desafio de acolher a distração para produzir consistência relacional e maior concentração na experiência da leitura em grupo.

Partindo de uma discussão do que entendemos por atenção e apoiado numa perspectiva ecológica, o objetivo deste texto é analisar a construção e os efeitos da Oficina da Palavra. A oficina foi realizada como uma pesquisa-intervenção baseada no método da cartografia (DELEUZE; GUATTARI, 1980; ROLNIK, 2014; PASSOS; KASTRUP; ESCÓSSIA, 2009; PASSOS; KASTRUP; TEDESCO, 2014; KASTRUP, 
2015; KASTRUP, 2019). A cartografia é um método de acompanhamento de processos que não separa a investigação da análise dos efeitos que ela provoca. $O$ texto analisa a Oficina como um dispositivo de cultivo da atenção conjunta.

\section{A ATENÇÃo PARA ALÉM DO ATO DE PRESTAR ATENÇÃO}

A complexidade do funcionamento da atenção pode ser percebida de forma destacada nos estudos do final do séc. XIX e início do séc. XX. A distinção proposta por W. James (1950) entre foco e margem da consciência indica o caráter seletivo, mas também fluido da atenção. Uma das grandes contribuições de James é situar a atenção no contexto da teoria do fluxo da consciência. A atenção responde pelo movimento da consciência. O funcionamento da atenção voluntária opera por puxões, por sacudidelas que buscam recolocar repetidamente no foco uma atenção cuja tendência é escapar a todo momento. Ou seja, a seleção operada pela vontade e pelo eu encontra resistência para sua efetivação, demandando um esforço reiterado para manter-se no foco. Tanto o foco quanto a resistência a ele constituem gestos atencionais importantes. Segundo E. Husserl (1998) se experimentarmos fixar a percepção num único objeto, podemos ter a medida da oscilação a que somos acometidos, independentemente do esforço da vontade consciente. A percepção vagueia e escapa do objeto visado e somos então capazes de flagrar a presença da atenção. Para P. Vermersch (2002), a atenção é o fundo de flutuação da cognição.

Por sua vez, H. Bergson (1922/2001) aponta a existência de uma atenção à duração ou atenção suplementar, que não se confunde com aquela voltada para a vida prática e para os imperativos da ação. A atenção à vida prática está envolvida nas atividades ordinárias da vida cotidiana, sendo, portanto, utilitária. Já a atenção suplementar caracteriza um mergulho na duração, evidenciada sobretudo na arte e na filosofia. Na mesma época, embora num outro contexto, S. Freud (1912) estabelece o conceito de atenção flutuante, destacando-a como aquela a ser exercida pelo analista no setting clínico, posto que necessária à escuta sintonizada 
com as associações inconscientes trazidas pelo paciente. Enfim, a atenção, em sua complexidade e amplitude, vai bem além do ato mental de prestar atenção, que é mobilizado na realização de tarefas pré-definidas, na solução de problemas e na aquisição de informações.

Quando a atenção é considerada sinônimo de prestar atenção, frequentemente associada à focalização, a distração é, por vezes, tomada como seu oposto - um regime de falta de atenção. No entanto, quando consideramos a complexidade dos regimes atencionais, percebemos que a distração possui uma importante função no processo atencional. Segundo Jean-Philippe Lachaux (2013), a boa atenção é uma atenção fluida e não rígida, que consegue gerir sua flutuação, deixando-se capturar de tempos em tempos. Para Lachaux (2013) assim como para Yves Citton (2014), a distração pode ser emancipatória e nos proteger da bolha que nos isola: ela permite que o diverso (de nós e em nós) participe e tenha lugar na nossa rede atencional. Entendida dessa maneira, a distração não é sinônimo de desatenção. A distração é um funcionamento onde a atenção vagueia, experimenta uma errância, fugindo do foco da tarefa para a qual é solicitada e indo na direção de um campo mais amplo, habitado por pensamentos fora do lugar, percepções sem finalidade, reminiscências vagas que têm em comum o fato de serem refratárias ao apelo da tarefa em questão. É curioso notar que o distraído pode ser alguém extremamente concentrado, não meramente desatento, mas cuja atenção se encontra em outro lugar. Poderíamos dizer que ele experimenta uma concentração aberta, destituída de intencionalidade e foco, que pode encontrar, mesmo sem buscar (KASTRUP, 2004).

A concentração aberta é dotada de duração e é experimentada, por vezes, como um tempo de desaceleração e espera por algo que não é do conhecimento e nem está sob controle do eu. Nesta perspectiva, concentração não é o mesmo que focalização. Pode haver concentração sem foco, como na prática de meditação (VARELA; THOMPSON; ROSCH, 1993) e focalização sem concentração. Distração e dispersão são também gestos atencionais distintos. A dispersão consiste num repetido deslocamento do foco atencional, que impossibilita a concentração 
(KASTRUP, 2004). Uma certa avidez de novidade impede a espessura temporal e a consistência da experiência. Aproxima-se, portanto, do que Boullier (2010) identifica como o estado de alerta, produzido pelas inúmeras demandas e estímulos que invadem nosso cotidiano. Para o autor, este estado de alerta produz uma contínua dispersão ou uma atenção apenas àquilo que surge como crise, como emergência, como digno de nota. Diferentemente da dispersão, o funcionamento errante da distração pode dar lugar a experiências de problematização e ter um papel importante nos processos educacionais (DE-NARDIN; SORDI, 2008), na medida em que possibilita a vivência de uma concentração aberta que acolhe e responde ativamente ao mundo.

Sem pretender entrar no exame detalhado e na análise dos desdobramentos e limites de cada uma dessas contribuições, parece-nos pertinente apontar a existência de uma discussão já presente no final do século XIX e adensada nos dias atuais que pode oferecer pistas interessantes para a análise e tratamento do TDAH e dos problemas atencionais no ambiente escolar. Nesta direção, a atenção vai muito além do gesto atencional individual de prestar atenção a um objeto. A questão que se coloca é como entender e cuidar de possíveis problemas atencionais que emergem na escola e em outras situações quando assumimos essa perspectiva.

\section{OS ECOSSISTEMAS ATENCIONAIS E A ATENÇÃO CONJUNTA}

Citton (2014) aponta que a atenção não é individual, mas sim individuante, coletiva e relacional. Em uma análise crítica do individualismo metodológico que marca os estudos da economia da atenção, define como mil folhas da atenção a superposição de mecanismos atencionais em múltiplos níveis entrelaçados e com funcionamentos diferentes entre eles. Um ecossistema atencional é um complexo folheado de atenções que coexistem, interpenetram-se e se co-afetam. Este complexo é também composto pela miríade de gestos atencionais que podem nele se atualizar. 
Essa visada nos leva a pensar que nunca prestamos atenção sozinhos. A atenção é conjunta quando nos grupos dos quais fazemos parte, como em uma sala de aula ou uma oficina, somos influenciados pela atenção daqueles que estão em torno de nós. Levando isso em consideração, o cuidado voltado para os problemas atencionais se amplia e revela ser uma alternativa para a centralidade da medicação.

A atenção conjunta - joint attention - é estudada pela filosofia da mente e por pesquisas empíricas da psicologia do desenvolvimento, da aprendizagem e da cognição social (SCAIFE; BRUNER, 1975; TOMASELLO, 2014). Ela é definida inicialmente como uma tendência em bebês, especialmente no final do primeiro ano de vida, de acompanharem a linha do olhar dos seus cuidadores, após estes últimos romperem o contato olho-a-olho com o bebê para observar algo presente no espaço em que ambos ocupam (SCAIFE; BRUNER, 1975; STERN, 1998). É definida por uma estrutura triangular, envolvendo geralmente dois sujeitos e um objeto, estando relacionada com a cognição social.

Com uma abordagem fenomenológica, Natalie Depraz (2010) parece ampliar essa análise ao considerar que a atenção conjunta inclui mutual awareness. Esta não é apenas o olhar mútuo, onde um olha para o outro. Para haver atenção conjunta não basta um seguir o olhar do outro em direção a um objeto. É preciso que o fato de dois sujeitos estarem presentes ao mesmo objeto seja manifesto e explícito para os dois. São identificados dois movimentos complementares: há atenção ao mesmo objeto e há atenção de um sujeito ao outro. A atenção partilhada é, então, um encontro dos sujeitos com o objeto e dos sujeitos entre si. O segundo movimento depende do primeiro. O laço entre os sujeitos repousa sobre a experiência de um mesmo objeto.

Há mutual awareness de partilhar um objeto, de viver/experimentar junto. Essa reciprocidade, no entanto, não é o mesmo que simetria, mas implica o cultivo de uma correspondência, na qual se experimenta a empatia, aqui entendida como disposição corporal de abertura conjunta. A partilha se dá sobre um fundo de 
disponibilidade e abertura, no qual torna-se possível entrar em ressonância e em vibração com o vivido, se dispondo a acolhê-lo.

Segundo Citton (2014), a atenção conjunta ocorre em situação de co-presença, tendo como características a reciprocidade (sem simetria), o esforço de sintonia afetiva e as práticas de improvisação. A atenção conjunta requer a co-presença sendo, portanto, um fenômeno presencial e local, experimentado por um número reduzido de participantes que se afetam mutuamente. Para explicar o esforço de sintonia afetiva, toma como modelo as situações de conversa, cuja etimologia do termo - convertere - sugere que se trata precisamente de saber inclinar-se, direcionar-se conjuntamente um para o outro. Citton destaca ainda a dimensão afetiva da atenção conjunta, que assegura a manutenção de uma conexão fundamental entre os participantes de um diálogo. É o afeto que faz a tecitura do vínculo e o prolongamento do contato, possibilitando a duração e consistência da troca atencional. Durante uma conversação, há um trabalho permanente de ajustamento recíproco entre a fala de um e a escuta do outro. Microgestos de simpatia, encorajamento, precaução ou acolhimento são percebidos nos encontros, criando uma atmosfera de ressonância afetiva. Ressonância que não pode ser pré-programada, demandando um trabalho constante de invenção. Assim, como última característica, a atenção conjunta sempre implica um certo grau de improvisação. Estar atento à atenção do outro é operar fora das rotinas e dos automatismos cognitivos, abrindo-se à imprevisibilidade dos encontros e à invenção conjunta.

$\mathrm{Na}$ atenção conjunta a co-presença, a reciprocidade, a sintonia afetiva e as práticas de improvisação e invenção se caracterizam menos como propriedades de ações do que como características que definem um ecossistema. Assim, o que define um ecossistema como favorável têm relação com o modo de interação atencional nele cultivado. O aspecto favorável de um ecossistema depende de como atenções co-existem, se interpenetram e se co-afetam num folheado complexo. Um ecossistema atencional torna-se favorável na medida em que os princípios da atenção conjunta são cultivados e experimentados. Por outro lado, um ecossistema 
é dito desfavorável quando, do ponto de vista da atenção conjunta, ele é precário e instável. Assim, o aspecto favorável ou desfavorável dos ecossistemas atencionais advêm do exercício dos princípios da atenção conjunta (reciprocidade, a sintonização afetiva e a improvisação), que favorecem a experiência relacional e a co-presença entre sujeitos e grupos. Citton (2014) aponta que a reciprocidade, por exemplo, presente na atenção conjunta é um antídoto para os problemas que possam advir de uma economia da atenção assimétrica e hierárquica, que precariza o aspecto relacional da atenção.

Nesta perspectiva, o autor afirma que mais que depositar nos pais a culpa do déficit de atenção de seus filhos, e, acrescentamos, mais que culpar a própria criança ou adolescente e mesmo os professores, trata-se de ultrapassar a posição de que esta é uma questão individual e pensá-la a partir do ecossistema atencional em jogo. No que concerne ao déficit de atenção ou ao diagnóstico de TDAH, este deve ser visto, ao menos em parte, como um sintoma da falta de reciprocidade atencional nas relações estabelecidas com as crianças: exige-se a atenção da criança, mas a ela pouca atenção é dedicada. O TDAH é entendido como sintoma da precariedade das conexões emocionais e afetivas mantidas com as crianças e da rigidez comunicacional que dificulta a possibilidade de invenção conjunta. São estas características que tornam famílias, escolas e grupos dos quais fazemos parte ecossistemas atencionais precários (CITTON, 2014). Assim, para cuidar de problemas atencionais torna-se necessário um trabalho conjunto de construção de ambientes ou ecossistemas atencionais favoráveis (CALIMAN; PRADO, 2018).

\subsection{EDUCAÇÃO COMO PRÁTICA ATENCIONAL}

Ampliando a compreensão e o estudo sobre a face conjunta da atenção nos encontramos com sua complexidade. Citton (2014) se interessa pelos ambientes humanos, tendo em vista sua estruturação pela atenção presencial de uns aos

outros. É nesse sentido que sublinha a importância da atenção conjunta no trabalho realizado na sala de aula. O objeto da aula é menos a informação a ser transmitida 
do que a construção de uma direção, de um esforço conjunto no qual nós percebemos melhor porque nos esforçamos para perceber com.

As ideias de Tim Ingold (2018) vão na mesma direção. Em "Anthropology and/as education", Ingold retoma questões que foram discutidas por John Dewey há mais de 100 anos, mas que continuam centrais no debate educacional atual. Ingold reforça a crítica de Dewey às perspectivas que definem a educação como um processo de transmissão de conhecimento e situa a educação como uma prática de atenção. Não é por transmissão, mas através da atenção que o conhecimento é gerado.

O papel central da atenção foi apontado pela concepção da educação como transmissão de conhecimento. Nesta perspectiva, a atenção é vista como uma capacidade individual que possibilita a seleção e captação da informação transmitida. No entanto, quando Ingold problematiza a compreensão da educação como transmissão, a importância da atenção é ainda mais enfatizada - ela torna-se, por excelência, o objeto da educação. O propósito da educação não é transmitir informação acerca de um mundo já dado, introduzindo conhecimento na mente vazia das crianças. É tornar o mundo presente, de modo que crianças e adultos, conjuntamente, possam "comunar", variando e produzindo conhecimento de forma responsiva e responsável. E este é um trabalho sobre a atenção.

Temos aí duas formas bem diversas de compreender a relação entre o conhecimento e a atenção, que alimentam projetos e práticas educacionais distintas e, por conseguinte, formas também diversas de cuidar das dificuldades dos processos atencionais. Na primeira, que compreende a educação como transmissão de conhecimento, encontramos uma atenção que deve colocar foco naquilo que já fora planejado e pensado, funcionando como um check out. Nesta perspectiva, a atenção é uma capacidade individual e natural, identificada a selecionar, prestar atenção e focar em uma informação transmitida pelo professor-emissor, que precisa ser adquirida pelo aluno-receptor. Se este caminho é interrompido, supõe-se que estamos diante de um déficit atencional. Quando a atenção é assim definida pouco 
ou quase nada é proposto como cultivo atencional e, nos dias atuais, quase sempre a única opção de tratamento é a prescrição farmacológica.

$\mathrm{Na}$ segunda forma de compreender o conhecimento, a tarefa educacional é tornar o mundo presente em sua comunalidade. Trata-se de uma perspectiva onde a atenção assume uma prioridade ontológica, sendo entendida como modo fundamental de estar no/com o mundo. Para Ingold (2018), quando cultivamos uma postura atenta ao/no mundo, correspondemos com ele, respondemos responsavelmente ao seu apelo de forma ativa. Nesta perspectiva, a atenção é o processo basilar da nossa constituição como seres relacionais. Segundo Boullier (2010), é na nossa postura atenta que manifestamos e criamos o laço que nos une e vincula a um ser/objeto. Fala-se de uma qualidade de presença e responsividade ativa ao que, do mundo, nos convoca. Como tal, a capacidade atencional resulta de um processo de aprendizagem que envolve sempre uma rede atencional em movimento. Nesta perspectiva, o objetivo da educação não é chegar a uma consciência do ou sobre o mundo, mas nos levar a uma correspondência com o mundo (INGOLD, 2018). Educar é cultivar uma consciência atenta não sobre o mundo, mas com o mundo. Trata-se, antes de tudo, de guiar a criança para o mundo, sendo, em última análise, uma prática de exposição e produção de sintonia com o mundo.

Para Citton (2014, p. 94), a sala de aula deveria ser vista como um grupo de pesquisadores no processo de inventar uma nova forma de produzir sentido sobre um campo do conhecimento. Ela é um ecossistema atencional que, mais do que o professor, assume a posição de agência. E é nesta perspectiva que as características que possibilitam o cultivo da atenção conjunta tornam-se fundamentais. O professor (e diríamos, também o estudante), precisa aprender a sentir, reconhecer e modular as ressonâncias afetivas que estruturam a sala de aula. Antes de ocupar-se da informação a ser transmitida, precisa começar a estabelecer e, sobretudo, manter a conexão afetiva que possibilita àqueles que estão em diálogo estarem no mesmo comprimento de onda emocional. É primeiramente em um nível emocional e afetivo que a conexão entre professor e aluno (e alunos entre si) é 
possibilitada. Quando a dinâmica em sala de aula privilegia a transmissão de conhecimento e a centralidade hierárquica do professor, compromete a criação de um ecossistema atencional favorável. Pouco ou quase nenhum espaço é dado à reciprocidade atencional e afetiva, à improvisação e invenção conjunta e ao ir e vir da distração.

A partir de uma perspectiva ecológica que ultrapassa o viés individualista e naturalista da atenção, o cuidado dos problemas atencionais surge como um trabalho de cultivo de correspondência e atenção conjunta concentrada e aberta, envolvendo a construção de ecossistemas atencionais favoráveis. É nesta direção que realizamos o trabalho na Oficina da Palavra.

\section{A OFICINA DA PALAVRA COMO UM ECOSSISTEMA ATENCIONAL}

Com o objetivo de descentralizar o lugar da medicação no tratamento dos problemas de atenção e de relação, construímos um dispositivo grupal e participativo de cuidado - a Oficina da Palavra. A Oficina foi assim nomeada pelo entendimento que a palavra poética poderia comparecer de diversas formas impressa e costurada em livro, caligrafada em papel, cantada em música ou falada. Nosso objetivo era promover o contato com a literatura como forma de movimentar palavras em nós - crianças, oficineiras e profissional do CAPSi - criando um ecossistema atencional convidativo ao diálogo, à participação e à partilha de experiências. A direção do trabalho foi a estratégia da Gestão Autônoma da Medicação (GAM) (CALIMAN, CÉSAR, 2020). Criada no Canadá e transposta de modo contextualizado para o Brasil em 2010, a GAM tem como proposta colocar em discussão as controvérsias em torno do uso do medicamento e desconstruir a relação hierárquica estabelecida entre usuários, familiares e profissionais de saúde mental $^{2}$. Seus princípios norteadores são o exercício da autonomia e da cogestão,

\footnotetext{
${ }^{2}$ A estratégia GAM no Brasil é praticada de forma coletiva, em grupo. Os princípios da autonomia e cogestão norteiam o modo de agir e se relacionar nos grupos GAM. A autonomia, nesse caso, não significa independência, ao contrário se realiza na referência à pluralidade de vínculos que se é capaz de estabelecer (KINOSHITA, 1996; PASSOS et al., 2013). É, portanto, uma autonomia que se
} 
que implicam necessariamente a construção de um plano de participação que, a nosso ver, pode ser experimentado através do cultivo da atenção conjunta (CALIMAN, et al, 2019; CALIMAN, et al, 2018).

A Oficina da Palavra foi um dispositivo de pesquisa criado para o desenvolvimento de um trabalho com crianças e adolescentes que vinham sendo atendidas no CAPSi. A partir de seu entendimento como dispositivo de cultivo de atenção conjunta, a proposta inicial foi experimentar a prática regular da leitura compartilhada da literatura, em voz alta e em roda. A Oficina ocorreu entre 2015 e 2017, acontecia uma vez por semana em uma sala ampla do CAPSi e cada encontro tinha em média uma hora de duração. Participaram dos encontros 10 crianças e adolescentes, entre 8 e 15 anos que, em sua maior parte, permaneceram até o final do trabalho. O critério de inclusão era a criança ou o adolescente ser atendido pela instituição, ter disponibilidade para frequentar os encontros semanais e fazer uso regular de pelo menos um psicofármaco. A participação era indicada pelos profissionais do CAPSi, com o acordo dos responsáveis. A Oficina foi oferecida como uma atividade eletiva, não sendo obrigatória a participação. Havia um horário marcado para o trabalho, mas era permitido que a criança ou adolescente chegasse atrasado ou se retirasse antes do término da atividade.

Todas as crianças que participaram da Oficina eram usuárias da rede pública de educação e de saúde mental da cidade de Vitória. Em sua maioria, crianças negras, moradoras da periferia da cidade e de instituições de acolhimento. Crianças acompanhadas por queixas escolares e também em situação de exclusão social. Algumas delas já faziam algum tipo de acompanhamento no CAPSi há mais de 5 anos, ou seja, sua experiência com a rede de saúde mental e com o uso de psicofármacos começara bem cedo em suas vidas. As três oficineiras, pesquisadoras-estudantes do curso de graduação em psicologia da Universidade

constrói no grupo, com diálogo e negociação de pontos de vista e que pressupõe interdependência. A cogestão, por sua vez, "é a gestão que se faz junto" (GUIA DO MODERADOR, p.10). Propõe produzir experiências compartilhadas entre todos os atores do grupo, procurando ampliar a comunicação e o diálogo sobre assuntos que usualmente são desconsiderados, como a experiência de uso de psicofármacos (GESTÃO AUTÔNOMA DA MEDICAÇÃO, 2014). 
Federal do Espírito Santo, e o grupo de pesquisa eram responsáveis pela seleção dos textos a serem lidos e demais elementos da dinâmica do trabalho, além do manejo dos encontros. Uma profissional de referência do CAPSi, indicada pelo serviço, participava regularmente da oficina. Todos os encontros foram registrados pelas oficineiras em diários de campo, que eram compartilhados com o grupo de pesquisa e discutidos em supervisões semanais. Ao longo deste texto, recorreremos a alguns trechos dos diários de campo.

A Oficina tinha como principal ponto de referência um tatame, onde a roda de leitura acontecia. Existia também uma mala cheia de livros infanto-juvenis, mesas, cadeiras, instrumentos musicais, alguns brinquedos. A Oficina procurou ser um ambiente de vida, mais que um espaço pedagógico para a realização de tarefas especificas. Segundo J. von Uexküll (2004), o conceito de ambiente de vida (Umwelt) é distinto do de meio físico, pois só existe para o vivo que o habita. $\mathrm{Na}$ mesma direção, Ingold (2018) usa o conceito de ambiente, tal como formulado por John Dewey - o ambiente não é apenas o que nos rodeia, mas aquilo que nos faz variar e que, ao mesmo tempo, varia conosco.

Ingold dá o exemplo do astrônomo olhando as estrelas. Para este, as estrelas, embora distantes, fazem parte do seu ambiente - ele se preocupa com elas, se ocupa e se envolve com elas. Porque elas the ocupam, as estrelas fazem com que ele varie, na medida em que seu olhar vagueia de estrela a estrela.

As estrelas questionam o astrônomo, despertam sua curiosidade, e ele é movido a responder. Essa resposta não é apenas uma reação, como se fosse um distúrbio da visão que irrompe na consciência, mas uma resposta que prolonga a tendência do próprio astrônomo que reside no desejo de conhecê-las melhor (INGOLD, 2018, p.05. Tradução nossa).

Há um exercício atencional na criação de nossos ambientes de vida. Esta se dá através de um cultivo de uma disponibilidade atencional através do qual objetos, pessoas e relações passam a ser objeto de (pre)ocupação uns para os outros - eles correspondem. $\mathrm{O}$ astrônomo corresponde com as estrelas, porque há o cultivo de uma "response ability". Para Ingold, esta habilidade de correspondência é uma 
aspiração, algo para ser construído conjuntamente, um esforço que demanda que cada um se abra para o outro ou se envolva com a preocupação do outro. Como veremos adiante, o conceito de correspondência evoca o de atenção conjunta, trazendo à cena as articulações entre humanos e não humanos.

Nesta direção, a Oficina da Palavra teve como objetivo criar um ambiente, um ecossistema atencional favorável, buscando produzir correspondência entre as crianças, oficineiras e crianças, profissional e oficineiras, todos com o livro e demais elementos ali presentes. Esta correspondência dependia de um trabalho de cultivo da atenção conjunta. Buscamos cultivar uma rede atencional múltipla e heterogênea, envolvendo humanos e não humanos. Visamos colocar em evidência e cartografar as mil folhas da atenção, procurando dar-lhes contorno por meio do cultivo de práticas de reciprocidade, sintonia afetiva e improvisação.

Foi frequentando a oficina com assiduidade que crianças e oficineiras passaram a fazer parte deste ecossistema e cultivaram a atenção conjunta. A aprendizagem por cultivo, tal como proposta por N. Depraz, F. Varela e P. Vermersch (2003) possui uma face de novidade e outra de sedimentação e enraizamento. O cultivo se dá em sessões consecutivas e regulares, tal como ocorre, por exemplo, na prática de meditação. Há repetição e algumas rotinas. 0 sentido da regularidade é criar um campo estável de sedimentação e acolhimento de experiências afetivas inesperadas, que fogem ao controle do eu. A regularidade das sessões tem como efeito a criação de uma familiaridade com tais experiências e, enfim, o desenvolvimento de uma atitude atencional de acolhimento. A noção de cultivo procura ressaltar que a aprendizagem resulta no aumento da força e da potência de gestos atencionais que já existem na cognição. Não parte, portanto, da ideia de déficit de atenção.

\subsection{O CULTIVO DE CONTORNOS ATENCIONAIS}

Os encontros começavam devagar, com a chegada das oficineiras. Elas se instalavam na sala e as crianças iam chegando. Antes da formação da roda as 
crianças brincavam, interagiam e conversavam de forma mais ou menos livre. Por vezes, as oficineiras propunham uma brincadeira que pudesse ir convocando a atenção, como o jogo Morto e Vivo. Diante da palavra "morto" as crianças deveriam agachar e diante da palavra "vivo" deveriam ficar de pé. Os comandos eram dados de forma sequencial e aleatória, sendo preciso que a criança estivesse de corpo presente no jogo e atenta às oficineiras e às outras crianças. Após algum tempo, tinha início a formação em roda.

Antes de começar a leitura, em alguns encontros era proposto o jogo da bolinha, no qual uma bolinha era jogada de um para outro participante, circulando entre eles. Quando alguém estava com a bola, era sua vez de falar brevemente para o grupo sobre algum assunto. O tema poderia ser sugerido por uma das oficineiras ou pelas próprias crianças. Coisas de que elas gostavam ou não gostavam, situações familiares e acontecimentos diversos surgiam na dinâmica da bolinha. Este era um momento de desaceleração dos movimentos sensório-motores e de ativação da atenção para o que o outro partilha, exercitando os princípios de uma atenção conjunta. Neste momento, era possível cada um aparecer com sua fala singular no grupo e também escutar uns aos outros. O jogo foi uma estratégia desenvolvida com o objetivo de dar um tempo para que as crianças deixassem o que estavam fazendo e se aproximassem aos poucos da roda e dos livros.

No entanto, nem sempre a criança dava sua atenção de imediato ou completamente ao que acontecia na roda. Uma cena do diário de campo descreve um desses momentos.

Durante o jogo da bolinha nos apresentamos e pedimos a Cauã (criança) para que se apresente também. Ele se afasta um momento do brinquedo com o qual está envolvido, se apresenta e, quase que ao mesmo tempo, lança a bolinha para que outra pessoa fale. Volta então ao brinquedo e a bolinha segue na roda. Apesar de Cauã não estar sentado formalmente na roda, sempre que é sua vez de falar, ele retorna suavemente, pensa no que vai falar, fala, e depois volta ao brinquedo. Enquanto brinca com os carrinhos, parece não estar presente à roda, mas está. (diário de campo) 
A presença à roda e ao brinquedo se alternavam e a atenção realizava um movimento de vaivém. Este movimento era acolhido na oficina e não imediatamente visto como problema, erro ou incapacidade. Não era, portanto, entendido como desatenção. Frente a uma proposição de atividade conjunta - diversa da tarefa pedagógica - tratava-se de acompanhar o movimento da atenção. Cuidávamos para que ela voltasse à roda, observando o ritmo e temporalidade de cada um e considerando a processualidade atencional. Buscava-se, então, acolher a distração e com ela ir aos poucos criando consistência na experiência partilhada.

Para que o cultivo da atenção conjunta pudesse se dar, a atenção das oficineiras também precisava ser cultivada. Utilizando em seu trabalho o método da cartografia, sua atenção deve ser concentrada e aberta. Definida como método por G. Deleuze e F. Guattari (1980), a cartografia requer uma atenção de qualidade especial, para além da seleção de informações e da focalização voltada para a representação das formas. A atenção do cartógrafo detecta signos, afetos e forças circulantes, ou seja, pontas do processo em curso. A detecção e apreensão de material, em princípio desconexo e fragmentado, de cenas e discursos, requer uma concentração sem focalização e uma abertura que também não se furta à distração (KASTRUP, 2019). Os diferentes gestos da atenção do cartógrafo possuem como diretriz o acesso ao plano coletivo de fluxos e forças moventes. Este plano é entendido como uma dimensão de virtualidade da subjetividade e do mundo, que coexiste com o plano das formas atualizadas e momentaneamente estabilizadas. A atenção cartográfica implica ainda na suspensão de julgamentos, expectativas e da busca de informações que fazem parte da atitude natural da cognição, devendo por isso ser cultivada. Uma das direções da oficina era dar contorno à atenção conjunta, concentrada e aberta, envolvendo crianças oficineiras e profissional do CAPSi. O desafio era produzir um ecossistema atencional favorável com crianças que chegavam com a atenção dispersa, pouco disponível à relação com outras crianças, com as oficineiras, com o livro e com a leitura em grupo.

$\mathrm{Na}$ oficina não havia um protocolo a ser aplicado, mas a aposta num aprendizado a partir da experiência. O trabalho visava a construção de contornos, 
não de limites. Não raro, deparamo-nos com a suposição de que às crianças diagnosticadas com TDAH faltam limites. Ao mesmo tempo, sabemos que na escola, ficar no limite ou ter limites distingue aqueles que se enquadram às normas daqueles que precisam ser "enquadrados" por meio de práticas disciplinares que são, em última instância, práticas de controle da atenção e do comportamento. Trata-se de reforço dos limites. Neste contexto, a imposição e o reforço de limites torna-se a direção do trabalho dos adultos com as crianças. Um trabalho que exige o foco atencional, tanto das crianças quanto dos professores e cuidadores. Diferentemente, na oficina, em lugar de procurar dar/impor limites, exercitávamos o cuidado participativo, baseado em contratações provisórias e na construção de contornos para o trabalho grupal.

Lachaux (2013) discute a relação entre atenção e controle. Normalmente pensamos em dominar a atenção por meio do esforço da vontade. Todavia, a atenção voluntária totalmente focada e individualmente controlada é um mito moderno, que hoje é atualizado como mito do controle de si. Por outro lado, muitas vezes assume-se que a atenção pode ser controlada externamente através da imposição de limites. Colocando o problema do que devemos entender por controle, Lachaux (p.13) traz o ensinamento de um mestre budista: se você quer "controlar" um carneiro ou uma vaca, comece por lhe dar muito espaço. Controle, neste caso, não é sinônimo de constrangimento, mas passa pela compreensão e pelo lâcher-prise (deixar ir), pelo desapego, pela abertura para acolher o que chega. A atenção é refratária à domesticação, mas pode ganhar contornos quando é cultivada conjuntamente, o que demanda um tipo de cuidado atencional.

Na Oficina da Palavra fomos construindo um contorno atencional, através dos combinados e pactuações. Um tempo importante era destinado ao processo de contratação do que seria feito na oficina, no qual algumas rotinas eram conjuntamente pactuadas. Diferentemente da definição de regras e limites fixos, quase sempre estabelecidos pelos adultos que propõem às crianças a realização de tarefas pré-definidas, os combinados na oficina eram conjuntamente criados, sendo 
repactuados quando não produziam mais o efeito esperado. É o que podemos acompanhar em um trecho de diário de campo.

Queríamos começar a ler os livros, mas vemos que os instrumentos musicais chegam mais e mais à roda. A demanda em relação à música tem chegado a nós com alguma frequência. Então, eu tento: "Bom, gente, antes de começarmos a ler, acho que podíamos fazer um acordo. Que só podemos tocar os instrumentos depois que a história acabar". (diário de campo)

Combinações como esta eram realizadas e sustentadas no grupo. Não era a regra o que se resguardava, mas a capacidade de criá-la, discuti-la e transformá-la, a depender do movimento do grupo. Dependia, portanto, de negociação e decisões compartilhadas, cujo efeito grupal era o aumento do sentimento de pertencimento e de correspondência, por meio do cultivo da atenção conjunta baseada em relações não hierárquicas.

A criação conjunta do ecossistema oficina e a pactuação participativa permitiam criar contornos no lugar de limites. O limite restringe e impossibilita o movimento. Por sua vez, o contorno permite a criação de consistência grupal, possibilitando o acolhimento de experiências afetivas inesperadas, dando a elas espaço e também uma direção. Trabalhava-se, assim, criando uma relação com a regra na qual ela funcionasse mais como contorno-fronteira do que como limite-barreira.

Joseph (criança) se levantou e foi novamente para a estante com brinquedos. Perguntou se a gente podia fazer uma banda e dissemos que ele podia trazer o pandeiro que já estava segurando e, com bastante cuidado, tocar alguma coisa enquanto eu lia a história, como uma trilha sonora. Joseph sugeriu que eu contasse a história cantando e aceitei a proposta. Durante o começo da história tudo foi cantado, com Joseph e Barbara (oficineira) me acompanhando no tambor e no chocalho. (diário de campo)

A insistência em fazer e refazer os acordos, quando necessário, compareceu como a melhor maneira de criar alguma disponibilidade para a leitura compartilhada e cultivar a atenção à experiência vivida na Oficina. 


\section{A LEITURA CONJUNTA DE LITERATURA}

Durante todo o tempo de funcionamento da Oficina da Palavra, a leitura de literatura foi utilizada como elemento central no trabalho com o grupo, ainda que em alguns encontros o livro tenha cedido espaço a outros dispositivos como lápis, canetinhas, tintas, cartazes, recortes, instrumentos musicais, brinquedos, fantoches e fantasias. Segundo Michele Petit, a leitura requer uma atenção levemente distraída, como ocorre quando uma passagem do texto faz com que levantemos os olhos da página do livro. Para Petit, talvez seja isto o que há de mais essencial na leitura, acima da decifração de uma mensagem. Afinal, ler "tem a ver com a possibilidade de ir e vir, com a possibilidade de entrar à vontade em um outro mundo e dele sair" (PETIT, 2009, p. 92). Embora Petit fale da leitura individual, a ideia de uma leitura que faz redes atencionais e comporta a distração são importantes na nossa discussão sobre a leitura em grupo como prática de cuidado.

$\mathrm{Na}$ Oficina da Palavra os livros e textos eram escolhidos com base no efeito inicial no grupo de pesquisa e nas oficineiras-pesquisadoras e também no possível efeito nas crianças. Buscamos ler livros que escapassem às histórias de significado único e às explicações fechadas. Trabalhamos com livros esburacados, que pudessem gerar passagem e abertura a outros modos de atenção e que suscitassem a invenção (CALIMAN et al, 2019). Experimentamos também fazer um uso esburacado de textos diversos, incluindo aqueles não explicitamente direcionados às crianças. Como estratégia de desaceleração cognitiva, por diversas vezes lançamos mão da apresentação demorada das ilustrações que acompanhavam o texto no livro. Juntos, inventamos diferentes modos de leitura. Ora líamos em conjunto, em voz alta, passando o livro de mão em mão na roda, dando vez para todos. Em outros momentos, uma das crianças ou uma das oficineiras fazia a leitura completa do livro. Houve vezes em que diferentes livros eram lidos em silêncio por cada um. Comentários, invenções e digressões eram muito bem-vindos. Nem sempre seguíamos a linearidade do texto. Vários ritmos conviviam: passávamos rápido por algumas frases e muito lentamente por outras. 
As variações nos modos de ler aconteciam em consonância com as pactuações e acordos realizados com as crianças na Oficina, exercitando a disponibilidade dos participantes à variação dos contornos atencionais. Para viver o que não estava pré-programado, tornava-se necessário um movimento de improvisação, característico da atenção conjunta. Ao abordar a prática da improvisação na educação, Citton (2014) afirma que a capacidade de invenção conjunta é determinante para que a sala de aula possa oferecer um ecossistema que mantém a atenção conjunta. As práticas de improvisação e invenção guardam um interesse pela descoberta de coisas não sabidas, não antecipadas até então. Ser atento à atenção do outro requer uma abertura ao risco de improvisar, deixando de lado rotinas pré-programadas.

Uma das dinâmicas de leitura consistia na proposição de que cada participante lesse uma página. O grupo era heterogêneo, existindo crianças com maior ou menor fluência de leitura. A ideia era que todos pudessem ler, ainda que por vezes isto ocorresse com a ajuda atenciosa da oficineira, quando surgiam dificuldades de leitura e compreensão. Também era respeitado o direito de não ler. A participação com a leitura em voz alta não era obrigatória. Esta podia se dar de outros modos como, por exemplo, na definição da ordem dos leitores, ouvindo ou simplesmente estando na sala, fazendo parte deste ecossistema atencional (CALIMAN et al, 2018). Como vemos no diário de campo:

Naquele dia, no trabalho com o primeiro livro, Lorena (criança) não quer ler. Não insistimos. A leitura roda de novo, Cauã (criança) está empolgado. Lorena de novo não quer ler quando chega sua vez. Ela simplesmente faz um não com a mão, nervoso e arisco. Pergunto se ela tem certeza que não quer ler. Ela responde que não. Apesar disso, assume um papel de "maestro". É ela que dita quem lerá a próxima parte. De repente, Lorena começa a ler. As palavras são ditas baixinhas antes de serem pronunciadas para o mundo. Quando emperra em alguma palavrinha, Bárbara (oficineira) vem ao socorro e ajuda. Havia certa sinergia nessa leitura. Todos acompanhavam. Não era uma leitura perfeita, mas acontecia. Sem desistência, sem choro, com vontade e afeição. O livro termina. Lorena parece estar gostando mais de ler na roda. No segundo livro daquele dia sua leitura já é menos conturbada e nervosa, e ela já não pronuncia as palavras em voz baixa. (diário de campo) 
Neste encontro da oficina há improvisações contínuas: acolher a criança que não quer ler e que, em esforços sutis de ali se manter, vai primeiramente entrando em silêncio, depois dando certo ritmo à leitura ao escolher o próximo que lerá e, lendo baixinho, até poder pronunciar as palavras para o mundo. Aqui o movimento de improvisação não se separa do esforço de sintonização afetiva entre oficineiras, crianças, livros e leitura, que vai possibilitando surgir a atenção conjunta. A leitura, mais que o ato de ler as palavras, é também uma leitura de gestos, atenção aos movimentos, às pausas, às iniciativas, ao tom e volume. Busca-se, assim, cultivar modos atencionais fluidos e em um ecossistema favorável, entendendo-os como efeitos e não condição de um processo de aprendizagem (KASTRUP, 2004).

\subsection{REDES DE ATENÇÃO NA LEITURA EM GRUPO}

A oficineira é uma espécie de outsider, um ser de fronteira, de borda (DELEUZE; GUATTARI, 1980; KASTRUP, 2008a; 2008b). Ela não é um centro, mas uma das linhas que concorre para envolver o grupo de leitura. Sua posição é de certa independência. Ora ela está lendo para o grupo, ora é tomada pelo próprio texto literário, num movimento de vaivém. Ora exerce um tipo de liderança, ora revela-se solitária. Por ocupar esta posição de fronteira, é um diferencial do grupo. Ela bordeja o grupo e, quando ela assume uma firme aliança com o texto, força os limites do grupo, abre linhas de fuga, e conduz às transformações que nele têm lugar. Exerce assim uma função ativa e desempenha um papel diferencial e heterogêneo em relação as crianças. Sua atenção concentrada e aberta surge como condição importante para que as próprias crianças experimentem o texto literário (KASTRUP, 2003). A onda provocada pela sintonia com o texto concorre para cativar a atenção das crianças:

Naquele dia, tudo o que a gente tenta não funciona para cativar a atenção dos meninos. Só Joseph (criança) está atento, na expectativa do começo da história. A oficineira decide começar a história assim mesmo. Ela pega o livro 'Bruxa, venha a minha festa' de Ardem Druce (2008) e começa. Joseph aguarda atento. Ela 
começa lendo: "Senhora bruxa, por favor, venha à minha festa!". João (criança) olha para a página com a imagem da bruxa, bate nela e diz: "Eu não quero ela na minha festa!". A oficineira segue com a leitura. Os personagens convidados para a festa vão chegando e, com eles, mudam os tons de voz usados para representar cada um. Nesse momento, Cauã e João (crianças) já estão concentrados na história. Quando a árvore vai ser convidada, ela fala sussurrando. O sussurro fez com que os meninos se interessassem ainda mais. Todos se aquietam e chegam mais para perto, para saber o que a árvore ia responder. Todos ficam bem concentrados até o final da história. Parece que aconteceu algum tipo de contágio. (diário de campo)

A ideia de contágio remete ao conceito de imitação, formulado por G. Tarde (1890/2001). Em Tarde, a imitação é definida pelas ideias de contágio e propagação.

Segundo Stengers (1987) a noção de propagação, formulada no campo das ciências biológicas, tem o sentido da propagação de um vírus ou uma bactéria. Diferentemente da propagação em Termodinâmica, que tende à uniformização e a anular sua causa, a propagação biológica é propagação de sua própria origem. Cada ser infectado torna-se, ele próprio, um centro de propagação. A causa fica inoculada em seu efeito. O desenho deste processo, que se faz com múltiplos pontos de bifurcação, é uma grande rede. Note-se que se pensa aqui do ponto de vista do sucesso do vírus. O "vírus" é a atenção à leitura.

O contágio envolveu as crianças e também a oficineira leitora. Segue seu relato.

Peguei esse livro porque estava eu mesma muito encantada com ele - era um dos meus livros preferidos enquanto criança. A riqueza das ilustrações e a consistência da história, ainda me emocionam, mesmo depois de adulta. O que aconteceu foi que comecei a ler sem muitas expectativas, mas com total entusiasmo. Pensava em fazer valer aquele encontro pelo menos para Joseph (criança), que prestava atenção. Mas alguma coisa aconteceu - não sei se foi o meu entusiasmo, o fascínio genuíno de Joseph frente à história, a ilustração monstruosamente realista ou se foi a mistura de tudo isso. Sem a gente chamar ou insistir, num movimento muito gradual, os meninos foram se deixando levar pela história. (diário de campo)

Todos os elementos descritos na cena acima parecem comportar a aposta na conexão sensível: era pelos afetos que as investidas eram feitas. O encanto da oficineira que se emociona com o livro, o fascínio da criança que lê, a força da 
ilustração, a leveza da postura das oficineiras que não insistem e não obrigam um certo tipo de presença, tudo isto se dá pelos movimentos intensivos dos afetos de vitalidade e pelo esforço de sintonia afetiva (STERN, 1998) que impulsionam o contágio - todos foram "deixando-se levar". Sempre permeados pela improvisação e por uma atenção ao mesmo tempo concentrada e aberta, tais encontros abriam processos de cultivo da atenção recíprocos e imprevisíveis.

\section{O MEDICAMENTO NA REDE DE CUIDADOS}

A Oficina da Palavra, como um dispositivo de pesquisa, dedicou-se a fazer do cuidado um cultivo atencional. Ser atento à atenção do outro em suas investidas e derivas tornava inseparável o cuidado do cultivo da atenção conjunta. A atenção requerida pelo trabalho de cuidado não é controle, mas, ao contrário, é a capacidade de cultivar a pessoa com suas próprias possibilidades e experiências e em situações sempre únicas. Não há no acompanhamento atento garantias de um fim esperado. Há o acolhimento do imprevisível, a possibilidade de abertura para o pluralismo das formas de relação e vida que são atenciosamente acompanhadas. Neste sentido a atenção é, por excelência, o gesto cognitivo do que Boullier (2010) define por cuidado cosmopolítico e que, a nosso ver, permite a ampliação das possibilidades de tratamento dos problemas atencionais.

O cuidado atencioso acolhe o pluralismo das formas de relação. O curioso é que isto significou a acolhida dos modos de relação das crianças com o diagnóstico de TDAH e com os medicamentos. O cultivo da atenção conjunta como modo de cuidado incluía tal acolhimento. Retirar a centralidade do medicamento do tratamento das crianças e adolescentes significava, paradoxalmente, romper com a invisibilidade de seu uso e de seus efeitos. A experiência com o medicamento é um dos fios da rede de atenção conjunta. Em um dos encontros da Oficina, uma criança comenta que dormiu na escola, por causa dos remédios de que faz uso. Fala que faz uso de um pela manhã, antes de ir para escola, e outro à noite, "para dormir 
mesmo". E comenta: "Não sei se vocês perceberam, mas é por isso que eu não estava alegre na semana passada. Era por causa do remédio".

A conversa aponta que por mais que o problema do uso e dos efeitos da medicação não estivesse explicitado todo o tempo, ele estava presente para as crianças como questão e por vezes como incômodo. O menino consegue perceber, por um movimento de atenção a si, os efeitos do medicamento em seu corpo, na qualidade da sua presença, em seus afetos e desempenho. Consegue também fazer a diferenciação entre um estado medicado e um estado não-medicado. Ao ser partilhada na conversa, a experiência com o medicamento convida aos outros participantes a trazerem também o modo como experimentam a medicação em suas vidas. Com isso, a relação com o medicamento passa a fazer parte daquele ecossistema atencional que construímos na oficina.

A Oficina da Palavra permitiu uma circulação de vozes, atenções e afetos das crianças e adolescentes, contando suas vidas e enunciando desejos. Cuidar, nesse sentido, significava acolher as diferentes formas de pertencimento, para gerar confiança e abertura, de modo que cada criança ou adolescente pudesse participar e se sentir à vontade no grupo. E nessa prática as oficineiras, sem dúvida, tinham um papel importante, acolhendo as experiências mais diversas, por mais difíceis, diferentes e intensas que fossem. É essa atenção cuidadosa que permitia partilha e negociação, que chamava sempre e novamente à participação, à conversa sobre o que se passava, à responsividade responsável.

Tal acolhida dependia não de controle, mas da criação conjunta de contornos atencionais em práticas diversas: no convite às crianças para construírem e desmontarem o espaço onde nos reuníamos, apropriando-se dele; no exercício difícil de acolhimento de movimentos caóticos, de irritação e discussões intensas entre elas; na conversa sobre medicamentos e na partilha de sofrimentos diversos, como não ter amigos, não se sentir compreendido, não ter uma casa. Como efeito, foi aos poucos surgindo uma grupalidade, um laço relacional, sustentado em múltiplos agenciamentos entre todos os participantes. 
Enfim, na Oficina da Palavra circularam fluxos materiais, afetivos, literários e químicos. Sua configuração e seu contorno eram relativamente tênues e sempre passíveis de ser desmanchados. A atenção circulava entre participantes e objetos, configurando múltiplas composições, sempre provisórias. Nada se assemelhava a uma situação em que um sujeito presta atenção a um objeto ou tarefa, de modo fixo. Nada próximo a um modelo binário atenção-desatenção. A metáfora do foco de luz, tão comumente referida ao trabalho da atenção, não funciona aqui, tampouco o modelo individualista. Estamos diante de flutuações e pousos atencionais, múltiplas modulações, conexões e desconexões, de mil folhas da atenção.

\section{REFERÊNCIAS}

BERGSON, H. (1922/2001). Introduction (deuxième partie): de la position des problèmes » [1922], La pensée et le mouvant dans OEuvres, André Robinet (éd.), Paris, Presses universitaires de France, p. 1271-1330, 2001 [1959].

BOULLIER, D. Por une conception cosmopolitique du care. Cosmopolitiques. Laboratoire des pratiques l'écologie politique, 2010. Disponível em:

https://blogs.mediapart.fr/dominique-g-boullier/blog/310810/pour-une-conception-cosmopoliti que-du-care. Acessado em: 29 maio 2020.

CALIMAN, L.; DOMITROVIC, N.Uma análise da dispensa pública do metilfenidato no Brasil: o caso do Espírito Santo, Physis, vol.23, n.3, p. 879-902, 2013.

CALIMAN, L. et al. O Cultivo Atencional como Exercício de Participação: Oficinar com Crianças na Saúde Mental. Ayvu, Rev. Psicol., v. 05, n. 01, p. 42-66, 2018.

CALIMAN, L. et al. Oficina da Palavra: literatura, infância e cultivo da atenção. Pesquisas e Práticas Psicossociais, v. 14, n. 1, janeiro-março, 2019.

CALIMAN, L.; PRADO, M. R. Prise de psychostimulants et attention: l'expérience de deux adolescents diagnostiqués TDAH au Brésil et en France. La nouvelle revue, Éducation et société inclusives, 85, p. 261-276, april, 2019.

CALIMAN, L.; CÉSAR, M. J. A GAM no ES: invenções com crianças, familiares e trabalhadores. Rev. Polis e Psique, v. 10, n. 2, p. 166-188, 2020.

CHAVES, F. A. M.; CALIMAN, L. Entre Saúde Mental e a Escola: A Gestão Autônoma da Medicação. Rev. Polis e Psique, V. 7, N. 3, p. 36-60, 2017.

CITTON, Y. Pour une écologie de l'attention. Paris: Le Seuil, 2014, p. 313. 
CONRAD, P. The discovery of hyperkinesis: notes on the medicalization of deviant behavior. Soc. Probl., v. 23, n.1, p. 12-21, 1975.

CONRAD, P. Expansion: from hyperactive children to adult ADHD. In: CONRAD, P. (org.). The medicalization of society: on the transformation of human conditions into treatable disorders. Baltimore: Johns Hopkins University Press, 2006, p.46-69.

DELEUZE, G.; GUATTARI, F. Mille Plateaux. Paris: Minuit, 1980, p. 645.

DEPRAZ, N. De I'“inter-attention" à l'attention inter-relationnelle. Le croisement de l'attention et de l'intersubjectivité à la lumière de l'attention conjointe. Symposium. V. 14, p.104-118, 2010.

DEPRAZ, N.; VARELA, F.; VERMERSCH, P. On becoming aware: A pragmatic of experiencing. Amsterdam/ Philadelphia: John Benjamin Publishing Company, 2003, p. 281.

DRUCE, A. Bruxa, bruxa, venha à minha festa. llustrações: Pat Ludlow. São Paulo: Editora Brinque-book, 2008.

FREUD, S. (1912). Conseils aux médecins sur le traitement psychanalytique. Disponível em https://psycha.ru/fr/freud/1912/conseils_medecins.html. Acesso em: 29 maio 2020.

GESTÃO AUTÔNOMA DA MEDICAÇÃO - Guia de Apoio a Moderadores. CAMPOS, Rosana et al. DSC/FCM/UNICAMP; AFLORE; DP/UFF; DPP/UFRGS: 2014, p. 44. Disponível em: https://www.fcm.unicamp.br/fcm/sites/default/files/paganex/guia gam moderador - versao para download julho 2014.pdf. Acesso em: 29 maio 2020.

GUIA DA GESTÃO AUTÔNOMA DA MEDICAÇÃO - GAM. CAMPOS, Rosana et al. DSC/FCM/UNICAMP; AFLORE; IPUB/UFRJ; DP/UFF; DPP/UFRGS, 2012, p. 71.

HUSSERL, E. De la sinthèse passive. Grenoble, França: Jérôme Milon, 1998, p. 431.

INGOLD, T. Anthropology and/as education. Routledge: New York, 2018, p. 94.

JAMES, W. The principles of Psychology. New York: Dover, 1950.

KASTRUP, V. A aprendizagem da atenção na cognição inventiva. Psicologia \& Sociedade, v. 16, n. 30, p. $07-16,2004$.

KASTRUP, V. Sobre livros e leitura. In: Kastrup, V.;Tedesco, S; Passos, E. (orgs.). Políticas da cognição. Porto Alegre: Sulina, 2008a, p. 241-266.

KASTRUP, V. Cartografias literárias. In: Kastrup, V.;Tedesco, S; Passos, E. (orgs.).

Políticas da cognição. Porto Alegre: Sulina. 2008b, p. 267-295.

KASTRUP, V. Production de subjectivité dans un atelier de lecture au Brésil. Chimères,v. 49, p.34-46, 2003. 
KASTRUP, V.La cartographie comme méthode: Pistes pour la pratique d'une recherche-intervention. Bulletin de Psychologie, v. 536, n.2, p. 125-134, 2015.

KASTRUP, V. Le fonctionnement de l'attention dans le travail du cartographe. Multitude, $v$. 75, n. 2, p.135-144, 2019.

KINOSHITA, R. T. Contratualidade e reabilitação psicossocial. In: PITTA, A. M. F. (org.).Reabilitação psicossocial no Brasil. São Paulo: Hucitec, 1996.

LACHAUX,J. P.Le Cerveau attentive: Contrôle, maîtrise et lâcher-prise. Odile Jacob: Paris, 2013, p. 385.

DE-NARDIN, N. H.; SORDI, R. O. Aprendizagem da atenção: uma abertura à invenção.Revista Iberoamericana de Educación, v. 47, 2008.

ORTEGA, F.; ZORZANELLI, R.; GONÇALVES, P. V. Academic and professional Tensions and debates around ADHD in Brazil. In: BERGEY, M.; FILIPE, A.; CONRAD, P.; SINGH, I. (eds.).Global perspectives on ADHD: Social dimensions of diagnosis and treatment in sixteen countries, Baltimore: Johns Hopkins University Press, 2018. p. 186-207.

PASSOS, E.; KASTRUP, V.; ESCOSSIA, L. (orgs.). Pistas do método da cartografia: pesquisa intervenção e produção de subjetividade. Porto Alegre: Sulina, 2009, p. 206.

PASSOS, E.; KASTRUP, V.; TEDESCO, S.(orgs.). Pistas do Método da Cartografia: a experiência da pesquisa e o plano comum (vol. 2). Porto Alegre: Sulina, 2016, p. 310.

PASSOS, E.et al. Autonomia e cogestão na prática em saúde mental: o dispositivo da gestão autônoma da medicação (GAM). Aletheia, Canoas, RS, Brasil, v. 41, p. 24-38, 2013.

PETIT, M. L'art de lire ou comment résister à l'adversité. París: Editions Belin, 2008.

ROLNIK, S.Cartografia sentimental.Porto Alegre: Sulina, 2014, p. 247.

SCAIFE, M; BRUNER, J.S. The capacity for joint visual attention in the infant. Nature, v. 253, n. 5489, p.265-266, jan., 1975.

STENGERS, I. Introduction: Propagation des concepts. In: STENGERS, I. (org.) D'une scienece à l'autre: des concepts nomads. Paris: Seuil, 1987,p.9-26.

STERN, D. The interpersonal world of the infant:a view from psychoanalysis and developmental psychology. Londres: Karnac Books, 1998.

TARDE, G. Les lois le l'imitation. Paris: Les empêcheurs de penserenrond, 2001, p. 447.

TOMASELLO, M. Joint Attention as Social Cognition. In: MOORE, C.; DUNHAM, P. J. (eds.) Joint Attention: its Origins and Role in Development(1995). New York: Psychology Press, 2014, p.103-130.

UEXKULL, J.Von mondes animaux et monde humain. Paris: Pocket, 2004, p. 188. 
VARELA, F.; THOMPSON, E.; ROSCH, E. L'inscription corporelle de l'esprit. Paris: Seuil, 1993, p. 382.

VERMERSCH, P. L'attention entre phénoménologie et sciences expérimentales: Eléments de rapprochement. Expliciter, v. 44, p.14-43, 2002.

Recebido em: 31/05/2020

Aprovado em: 31/08/2020 